\title{
Preparation, Characterization and Thermal Expansion of Pr Co-Dopant in Samarium Doped Ceria
}

\author{
V. Venkatesh, V. Prashanth Kumar, R. Sayanna, C. Vishnuvardhan Reddy \\ Dept.of Physics, Osmania University, Hyderabad, INDIA \\ Email: reddycvv@yahoo.com
}

Received 2012

\begin{abstract}
The compositions $\mathrm{Ce}_{0.8-\mathrm{x}} \mathrm{Sm}_{0.2} \mathrm{Pr}_{\mathrm{x}} \mathrm{O}_{2-\delta}(\mathrm{X}=0,0.02,0.04,0.06)$ were prepared through the sol-gel route. The effect of Pr addition on the crystal structure, densification and thermal expansion of $\mathrm{Ce}_{0.8} \mathrm{Sm}_{0.2} \mathrm{O}_{2-\delta}$ was studied. The phase identification and morphology was studied by X-ray diffraction (XRD) and scanning electron microscopy (SEM). X-ray diffraction analysis showed that all the samples exhibit a fluorite structure. The lattice parameters were determined by X-ray powder diffraction. Lattice parameters and volume of the unit cell increases with Pr doping. Density of the all samples is more than $90 \%$ of theoretical density. The thermal expansion was measured using dilatometric technique in the temperature range $30-1000^{\circ} \mathrm{C}$. It was observed that the thermal expansion increased linearly with increasing temperature for all the samples.
\end{abstract}

Keywords: Solid Oxide Fuel Cells; Sol-Gel; X-Ray Diffraction; Scaning Electron Microscopy; Thermal Expansion

\section{Introduction}

Solid oxide fuel cells (SOFCs) convert chemical energy directly into electrical energy with high efficiency, environmental friendliness, and great flexibility in the choice of fuel [1-3]. Electrolytes used for SOFCs are usually the main components determining the performance of the fuel cell. Yttria stabilized zirconia (YSZ) is well established electrolyte, which can be used in commercial SOFCs. A typical high-temperature SOFC uses $8 \mathrm{~mol} \%$ YSZ as electrolyte, usually operated at temperatures as high as $800-1000^{\circ} \mathrm{C}$ to obtain the required level of ionic conductivity. However, such high operating temperatures result in expensive fabrication costs and accelerate the degradation of fuel cell systems. Therefore, strong motivation to search for new, improved oxide-ion electrolytes at intermediate temperatures $\left(400-700^{\circ} \mathrm{C}\right)$ persists. Lowering the operating temperature to an intermediate temperature $\left(400-700^{\circ} \mathrm{C}\right)$ significantly enhances the long-term performance stability, lessens sealing problem, widens the material selection, and allows the use of low-cost metallic interconnects, thereby accelerating the commercialization of SOFC technology[4]. Doped ceria has been acknowledged as a potential electrolyte material for IT-SOFCs because of their high ionic conductivity and good compatibility with electrodes[5-6].

The ionic conductivities of ceria based electrolytes doped with various dopants(e.g., $\mathrm{Sm}^{3+}, \mathrm{Gd}^{3+}, \mathrm{Y}^{3+}, \mathrm{Ca}^{2+}, \mathrm{Sr}^{2+}$ ) at different dopant concentrations have been extensively investigated [7-13]. $\mathrm{Sm}^{3+}$ is considered one of the best dopants for ceriabased solid electrolytes currently available [14-16]. The codoping technique has been effective method for improving the conductivity and leads to thermal expansion match between the electrodes and electrolyte in ceria based electrolytes for the IT-SOFCs [7].

In the present paper we report the sol-gel synthesis of $\mathrm{Ce}_{0.8-\mathrm{x}} \mathrm{Sm}_{0.2} \mathrm{Pr}_{\mathrm{x}} \mathrm{O}_{2-\delta}$ for $(0 \leq \mathrm{x} \leq 0.06)$. The powder characteristics such as crystallite size, surface area and thermal expansion have been determined as a function of $x$.

\section{Experimental}

The sample with the general formula $\mathrm{Ce}_{0.8-\mathrm{x}} \mathrm{Sm}_{0.2} \mathrm{Pr}_{\mathrm{x}} \mathrm{O}_{2-\delta}(\mathrm{x}=0$, $0.02,0.04,0.06)$ were synthesized by sol-gel method. Ceric ammonium nitrate $\left(\left(\mathrm{NH}_{4}\right)_{2} \mathrm{Ce}\left(\mathrm{NO}_{3}\right)_{6}\right)$ (Merck, 99\%), samarium oxide $\left(\mathrm{Sm}_{2} \mathrm{O}_{3}\right)$ (Himedia-99.9\%) and Praseodymium oxide $\left(\mathrm{Pr}_{6} \mathrm{O}_{11}\right)$ (Himedia-99.9\%) were used as starting materials. Stoichiometric amounts of samarium oxide and praseodymium oxide powders were mixed with nitric acid and placed on a heater at $50^{\circ} \mathrm{C}$ to convert into nitrates. Stoichiometric amount of Ceric ammonium nitrate was dissolved in distilled water. Nitrate solutions were added to Ceric ammonium nitrate solution and stirred properly. Citric acid was added to the whole solution in 1:1 molar metal ratio to bind the metal ions. The $\mathrm{pH}$ of solution was adjusted $₫ 0$ by adding ammonia. After evaporating the water, ethylene glycol was added and heated at about $90^{\circ} \mathrm{C}$ until a gel-type solution was formed. The gel was dried at $150^{\circ} \mathrm{C}$ and then decomposed at $250{ }^{\circ} \mathrm{C}$ in air for $2 \mathrm{~h}$ to decompose nitrates and all organic materials. The resultant ash was ground to get a fine homogeneous powder after that the powder was calcined at $600^{\circ} \mathrm{C}$ for 2 hours. The oxidation of $\mathrm{Ce}^{3+}$ to $\mathrm{Ce}^{4+}$ occurred during this stage [5].

Intermediate calcination and grounding of the synthesized powders were finally pressed in to pellets dimension $10 \mathrm{~mm}$ in diameter $2 \mathrm{~mm}$ in thickness, and then pellets were sintered in air at $1300^{\circ} \mathrm{C}$ for 4 hours. The densities of sintered samples measured in xylene by Archimedes principle. The sintered samples have above $90 \%$ of the theoretical density.

Phase identification and crystallographic information of the samples were obtained from the X-ray data by using PANalytical X'Pert Pro X-ray diffractometer (XRD) with $\mathrm{Cu} \mathrm{K} \alpha$ radiation $(\lambda=1.54056 \AA$ operated at $40 \mathrm{kV}$ and $30 \mathrm{~mA})$ at room tem- 
perature in the range $22^{2} 2 \theta \leq 80^{\circ}$. Lattice parameter s were calculated by fitting the observed reflections with a least-square refinement UNIT CELL program. The surface morphology of the samples was observed using the scanning electron microscopy (SEM) (ZIESS EVO-18).

The Thermal expansion measurements were carried out with a Netzsch push-rod dilatometer (DIL: Model Netzsch DIL 402 PC, Germany). Thermal expansion coefficient of the sintered sample pellets were measured using a constant heating rate of $3^{\circ} \mathrm{C} / \mathrm{min}$ in the temperature range $30-1000^{\circ} \mathrm{C}$. The rectangular samples of dimension $25 \mathrm{~mm} \times 6 \mathrm{~mm} \times 6 \mathrm{~mm}$ were used these measurements. The rectangular pellets were pressed in a hydraulic press and sintered at $1300^{\circ} \mathrm{C}$. Standard aluminum $\left(\mathrm{Al}_{2} \mathrm{O}_{3}\right)$ reference sample was used for the temperature calibration.

\section{Results and Discussion}

The X-ray diffraction patterns of the prepared system $\mathrm{Ce}_{0.8-\mathrm{x}}$ $\mathrm{Sm}_{0.2} \mathrm{Pr}_{\mathrm{x}} \mathrm{O}_{2-\delta}$ are shown in Figure 1. Praseodymium as co- dopant into samarium doped ceria (SDC) ceramics sintered at $1300^{\circ} \mathrm{C}$ shows cubic fluorite structure with space group Fm3m (JCPDS powder diffraction File no.75-0158).

The crystallite size $\left(\mathrm{D}_{\mathrm{XRD}}\right)$ is calculated according to the Scherrer equation[17].

$$
\mathrm{D}_{\mathrm{XRD}}=0.9 \lambda /(\beta \cos \theta)
$$

where, $\lambda$ is the wavelength of the radiation, $\theta$ is the diffraction angle and $\beta$ is the full width in radians at half maximum intensity of powder pattern at $2 \theta$. The crystallite sizes of the sample powders calculated by the Scherrer formula are in between $46 \mathrm{~nm}$ and $59 \mathrm{~nm}$.

In praseodymium, the ionic state changes from $\operatorname{Pr}^{3+}$ to $\mathrm{Pr}^{4+}$ under oxidizing process [18]. The introduction of $\mathrm{Pr}^{4+}$ into $\mathrm{Ce}^{4+}$ can cause a small shift in the ceria peaks. This shift is indicative of a change in the lattice parameter. The lattice parameter is increased with an increase $\mathrm{Pr}$ content due to the difference in ionic radii of $\mathrm{Ce}^{4+}(0.96 \AA)$ and $\operatorname{Pr}^{4+}(1.14 \AA)$ in an oxide solid solution [19]. As praseodymium content increases, the lattice parameter increases, this is indicates that $\mathrm{Pr}$ has been dissolved into Ce site in $\mathrm{Ce}_{0.8-\mathrm{x}} \mathrm{Sm}_{0.2} \mathrm{Pr}_{\mathrm{x}} \mathrm{O}_{2-\delta}$ and in single phase structure

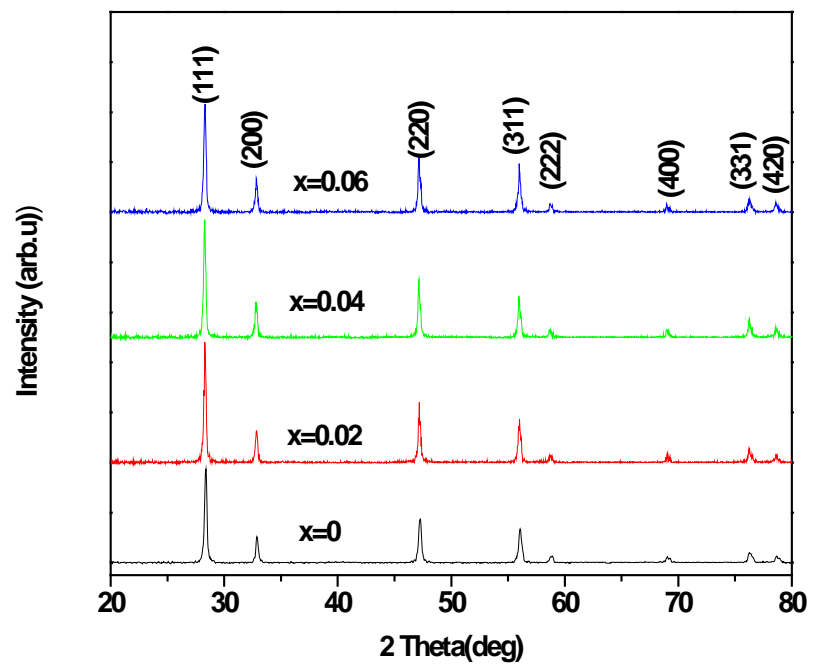

Figure 1. XRD pattern of $\mathrm{Ce}_{0.8-\mathrm{x}} \mathrm{Sm}_{0.2} \mathrm{Pr}_{\mathrm{x}} \mathrm{O}_{2-\delta}(0 \leq \mathrm{x} \leq \mathbf{0 . 0 6})$. is formed. The lattice parameters, the unit cell volume and the type of structure of the system are presented in the Table.

\begin{tabular}{cccc}
\hline $\mathrm{x}$ & Structure & $\mathrm{A}(\AA)$ & Volume $\left(\AA^{3}\right)$ \\
\hline 0 & Cubic & 5.432 & 160.28 \\
0.02 & Cubic & 5.436 & 160.71 \\
0.04 & Cubic & 5.437 & 160.77 \\
0.06 & Cubic & 5.438 & 160.82 \\
\hline
\end{tabular}

Figure 2 show the SEM photographs are clears that less porous is residual, in accordance with the relative density of the sintered pellets.

Relatively dense samples, with density greater than $90 \%$ of the theoretical values are required for the measurement of TEC [20].

$$
\mathrm{D}_{\mathrm{TH}}=z \times M / 0.6023 \times V
$$
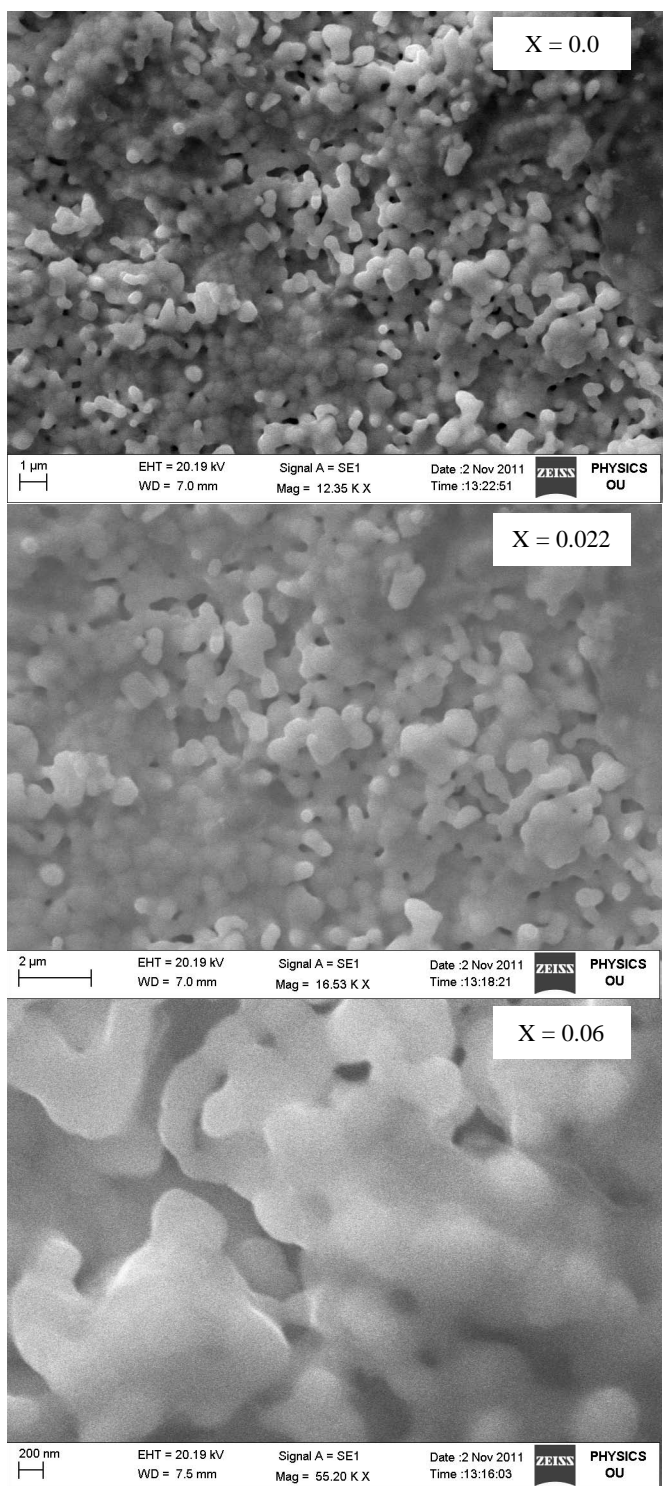

Figure 2. SEM Photographs of $\mathrm{Ce}_{0.8} \mathrm{Sm}_{0.2} \mathrm{O}_{2-\delta}, \mathrm{Ce}_{0.78} \mathrm{Sm}_{0.2} \mathrm{Pr}_{0.02} \mathrm{O}_{2-\delta}$ and $\mathrm{Ce}_{0.74} \mathrm{Sm}_{0.2} \mathrm{Pr}_{0.06} \mathrm{O}_{2-\mathrm{d}}$. 
Theoretical density can be calculated using by equation (2) where V (in $\AA 3$ ) is the volume of the unit cell as determined by $\mathrm{XRD}, \mathrm{M}$ (in atomic mass units) is the mass of one formula unit, $\mathrm{z}$ is the number of such formula units in one unit cell of the crystal. The possible departures from stoichiometry have not been taken into account in calculating M. The bulk density (d), the theoretical density (dth), and d/dth (\%) are summarized in Table 1. All samples have densities above $90 \%$ of the theoretical value.

The thermal expansion coefficients of electrolyte and electrodes should match, to avoid micro-cracks in between them for the operati0n of SOFC device at high temperatures. The thermal expansion data of $\mathrm{Ce}_{0.8-\mathrm{x}} \mathrm{Sm}_{0.2} \mathrm{Pr}_{\mathrm{x}} \mathrm{O}_{2-\delta}(\mathrm{x}=0,0.02,0.04,0.06)$ obtained in the temperature range $30-1000^{\circ} \mathrm{C}$ in air is shown in Figure 3. The thermal expansion depends on the electrostatic forces within the lattice, which depends on the concentration of positive and negative charges and their distances within the lattice. The thermal expansion increases due to the decrease in attractive forces. Thermal expansion of a lattice is characterized by a steady thermal expansion coefficient $(\alpha)$, for a certain structure and fixed oxygen to metal stoichiometry. The slope of thermal expansion curves for all the compositions are increased with temperature.

The thermal expansion coefficients (TEC) are calculated from the thermal expansion curves and values are listed in Table 2. The results of the present study are in contrast with the reported values. [10, 12-13, 21-24]. The disparity in the results may be due to preparation condition, non-stoichiometry of oxygen and oxidizing process of Pr.

Table 1. Density measurements of $\mathrm{Ce}_{0.8-\mathrm{x}} \mathrm{Sm}_{0.2} \mathrm{Pr}_{\mathrm{x}} \mathrm{O}_{2-\delta}(0 \leq \mathrm{x} \leq 0.06)$.

\begin{tabular}{cccc}
\hline $\mathrm{x}$ & Bulk Density (d) & Theoretical Density $\left(\mathrm{d}_{\mathrm{th}}\right)$ & $\mathrm{d} / \mathrm{d}_{\mathrm{th}} \%$ \\
\hline 0 & 6.769 & 7.216 & 93 \\
0.02 & 6.934 & 7.197 & 96 \\
0.04 & 6.725 & 7.195 & 93 \\
0.06 & 6.818 & 7.192 & 94 \\
\hline
\end{tabular}

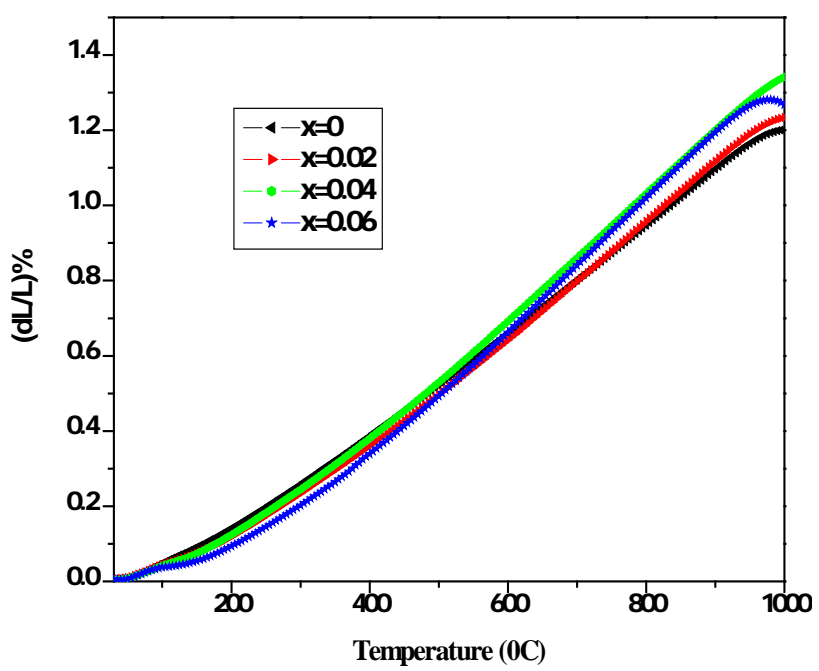

Figure 3. Temperature variation of thermal expansion of $\mathrm{Ce}_{0.8-\mathrm{x}}$ $\mathrm{Sm}_{0.2} \operatorname{Pr}_{\mathbf{x}} \mathrm{O}_{2}(0 \leq x \leq 0.06)$.
Table 3. Thermal expansion co-efficient of $\mathrm{Ce}_{0.8-\mathrm{x}} \mathrm{Sm}_{0.2} \operatorname{Pr}_{\mathrm{x}} \mathrm{O}_{2-\delta}(0 \leq \mathrm{x}$ $\leq \mathbf{0 . 0 6})$.

\begin{tabular}{cccc}
\hline & \multicolumn{3}{c}{ TEC $\left(10^{-6} /{ }^{\circ} \mathrm{C}\right)$} \\
\cline { 2 - 4 } & $30-600^{\circ} \mathrm{C}$ & $30-800^{\circ} \mathrm{C}$ & $30-1000^{\circ} \mathrm{C}$ \\
\hline 0 & 11.51 & 12.25 & 12.32 \\
0.02 & 11.17 & 12.36 & 12.66 \\
0.04 & 12.03 & 13.31 & 13.78 \\
0.06 & 11.52 & 13.18 & 13.02 \\
\hline
\end{tabular}

\section{Conclusions}

Praseodymium and samarium co-doped ceria samples $\mathrm{Ce}_{0.8-\mathrm{x}}$ $\mathrm{Sm}_{0.2} \mathrm{Pr}_{\mathrm{x}} \mathrm{O}_{2-\delta}(\mathrm{x}=0.00,0.02,0.04$ and 0.06$)$ are successfully synthesized through the sol-gel method. Dense ceramics are obtained by sintering the pellets at $1300^{\circ} \mathrm{C}$ for 4 hours. The relative densities are over $90 \%$ of the theoretical density and these results are consistent with the SEM studies. The lattice parameter increased with increasing Pr content. Thermal expansion increased linearly with increasing temperature for all the samples. The values of thermal expansion coefficients of all the compositions are in the range of $12.25 \times 10^{-6} /{ }^{\circ} \mathrm{C}$ to $13.31 \times$ $10^{-6} /{ }^{\circ} \mathrm{C}$. The present co-doped ceria materials can be used as possible electrolyte material for IT-SOFC applications.

\section{Acknowledgements}

One of the author, V.Venkatesh, thanks to the University Grant Commission (UGC), New Delhi, India for the financial assistance under the scheme of Research Fellowships in Science for Meritorious Students (RFSMS).

\section{REFERENCES}

[1] Xingbao Zhu, Zhe Lu, Bo Wei, Yaohui Zhang, Xiqiang Huang, Wenhui Su, Int J Hydrogen Energy, vol.35, 2010, pp. 6897-904.

[2] J. Nielsen, A Hagen, Y.L. Liu, Solid State Ionics, vol.181, 2010, pp. 517-24.

[3] Yicheng Liou, Songling Yang, J Power Sources, vol.179, 2008, pp.553-9.

[4] N.P. Brandon, S. Skinner, B.C.H. Steele, Annu. Rev. Mater. Res., vol. 33, 2003, pp. 183.

[5] B.C.H. Steele, Solid State Ionics, vol.129, 2000, pp. 95-110.

[6] C.M. Lapa, D.P.F. De Souza, F.M.L. Figueiredo, F.M.B. Marques. Int J Hydrogen Energy, vol.35, 2010, pp. 2737-41.

[7] S.Omer, E.D.Wachsman, J.C.Nino, Solid State Ionics, vol.178,2008, pp. 1890-7.

[8] S.Omer, E.D.Wachsman, J.C.Nino, Solid State Ionics, vol.177,2006, pp. 3199.

[9] H.Inaba, H.Tagawa, Solid State Ionics, vol. 83, 1996, pp. 1.

[10] N.Kim, BH.Kim, D.Lee, J.Power Sources, vol. 90, 2000, pp. 139.

[11] S.Lubke, H.D.Wiemhofer, Solid State Ionics, vol.117, 1999, pp. 229.

[12] V.Prashanth Kumar, Y,S.Reddy, G.Prasad, P.Kistaiah, C.Vishnuvardhan Redyy, Mater.Chem.Phys, vol.112, 2008, pp. 711.

[13] S.Ramesh, V.Prashanth Kumar, P.Kistaiah, C.Vishnuvadhan Redyy, Solid State Ionics, vol. 181, 2010, pp. 86. 
[14] Yifeng Zheng, Liqiang Wu, Haitao Gu, Ling Gao, Han Chen, Lucun Guo. J Alloys Compd, vol.486, 2009, pp. 586-9.

[15] Yifeng Zheng, Shoucheng He, Lin Ge, Ming Zhou, Han Chen, Lucun Guo, Int. J of Hydrogen Energy, vol.36, 2011, pp. 5128-5135

[16] K. Eguchi, T. Setoguchi, T. Inoue, H. Arai. Solid State Ionics, vol.52, 1992, pp. 165-72.

[17] L.V. Azaroff, Elements of X-Ray Crystallography, McGraw-Hill, New York, 1968, 552.

[18] S.Lubke, H.D.Wiemhofer, Solid State Ionics, vol.117, 1999, pp. 229.
[19] R.D.Shannon, Acta Cryst., vol. A32, 1976, pp. 751.

[20] J. H. Kuo, H. U. Anderson, and D. M. Sparlin: J. Solid State Chem., vol.83, 1989, pp. 52.

[21] S.R.Bishop, K.L.Dunkun, E.D.Wachsman, Electrochim. Acta, vol.54, 2009, pp. 1436.

[22] H.Hayashi, M.Kanoh, C.J.Quan, H.Inaba, S.Wang, M.Dokiya, H.Tagawa, Solid State Ionics, vol.132, 2000, pp. 227.

[23] F.Tietz, Ionics, vol.5, 1999, pp. 129.

[24] S.Wang, R.Zheng, A.Suzuki, T.Hashimoto, Solid State Ionics, vol.174, 2004, pp. 157. 